\title{
Chinese Cultural Empowerment in Short Video New Media Under the Phenomenon of Pan-Entertainment - A Comparative Study Based on Li Ziqi and Blondie in China
}

\author{
Xichang Li \\ Department of Culture and Communication, University of International Relations, Qinglongqiao Street, Hai Dian \\ District, Beijing, China \\ xi_change@sina.cn
}

\begin{abstract}
With the rapid development of Chinese short videos in the new media era, people are in a communication field full of pan-entertainment. Some short video bloggers, such as Chinese and foreign food culture short video blogger Li Ziqi and Australian Amy(Blondie in China), strive to output quality content by showing the infectious power and charm of Chinese culture, and carry out cultural empowerment in the short video communication of "culture+" to continuously improve and purify the development status of China's short video field in order to achieve high-quality.
\end{abstract}

Keywords: Pan-Entertainment, short video, Chinese Food Culture, Cultural Empowerment

\section{INTRODUCTION}

Entertainment is the communication content that can best establish a certain relevance to the public. The rapid development of media in the Internet context has led to the emergence of pan-entertainment, with consumerism and hedonism becoming central. The short video industry is the most typical example. Nowadays, media is considered as the fastest growing consumer product. Although the overall macro context tends to be pan-entertainment, the media culture phenomenon has changed. Many Chinese and foreign folk short video bloggers have become popular with their unique contents and styles. The extent of their popularity and audience coverage form the image of Chinese culture. This article takes two Chinese and foreign short video bloggers as examples, combining the current background of new media and pan-entertainment, to empower traditional Chinese culture in modern life and show the world China's cultural life and cultural concepts through the current easy-to-understand folk communication methods.

\section{CHINESE CULTURAL EMPOWERMENT IN THE NEW MEDIA ENVIRONMENT}

\subsection{New Media Environment and Short Videos in China}

In recent years, with the rapid development of Internet and mobile terminal technologies, China's new media environment has become more and more open. According to The 46th Statistical Report on Internet Development in China published by China Internet Network Information Center (CNNIC), as of December 2020, the size of China's Internet users reached 989 million, an increase of 85.4 million from March of the same year, and the Internet penetration rate reached $70.4 \%$. Among them, the scale of short video users is 873 million, accounting for $88.3 \%$ of the overall Internet users[1]. At present, the Chinese short video industry market is growing rapidly, covering an obvious advantage in expanding the scale of users.

With the premise of policy, technology protection and the joint promotion of industry supply and demand, China's short-video marketing is becoming standardized and mature. According to data provided by iResearch, 
the "entertainment + monetization" model of short video marketing has been increasingly recognized since the rise of short video in China in 2016. In 2018, short video entered a period of rapid development, with operating revenue exceeding 14.01 billion RMB, up $520.7 \%$ year-on-year[2]. Driven by content providers, platform monetization needs, user traffic and advertising budgets, the development of short video marketing is characterized by rich production content, wide adaptability and strong communication capabilities. According to Online Entertainment: A New Wave of Media Globalization, it shows that "In the eight years since the partner plan launched, YouTube has secured more than 2 million YouTube partners worldwide who derive some revenue from their uploaded content.[3]" Short videos have become an emerging industry in the new media era.

In Amusing Ourselves to Death, Neil Postman mentions: "He (Huxleyan) was trying to tell us that what afflicted the people in Brave New World was not that they were laughing instead of thinking, but that they did not know what they were laughing about and why they had stopped thinking"[4]. In all pan-entertainment systems, there are no solemnity, nobility and profundity any more. Value orientation is deviated, and the curious gossip psychological needs of the public are satisfied through superficial and empty entertainment information, which greatly reduces the public thinking and public rational ability of the audience.

\subsection{Cultural Empowerment in the New Media Perspective}

In his book, Team of Teams: New Rules of Engagement for a Complex World, New York Times bestselling author General Stanley McChrystal defines "empowerment" as follows: Empowerment means empowering others. From the leader's perspective, it means believing in team members, constantly exercising members' abilities, improving organizational structure, and avoiding deep-well orders[5]. In the short video bonus period, cultural empowerment means that a certain culture gives something a deep connotation or derivation, that is, the mode of "culture+". When it comes to cultural empowerment, three elements need to be clarified. First, cultural empowerment must have a core culture. If there is no development of the core, then the concept of empowerment is hollow and groundless. Second, cultural empowerment requires a development path, which is a new path derived from the basic culture and is not the same as the traditional development path. Finally, the purpose of cultural empowerment is to build a complete system so that the core culture and other empowered cultures can be harmonized to create greater value for the subject. Culture itself is in need of a communication medium or related means to manifest. "The media is the message, extensions of the human body"[6] which makes culture gradually transform into a cultural consumer product, attracting a wider audience and expanding the effect of communication through empowerment.

Faced with the phenomenon of Pan entertainment, many Chinese short video creators have awakened their consciousness and are committed to promoting the transformation of content to high quality. The fine development of vertically subdivided content has revealed a trend. Media is the carrier of culture. By accurately positioning the audience groups and needs, short video bloggers develop multiple types of subdivided content such as beauty, dressing, food and fitness, highlight the characteristics of personalization and information specialization, and spread acceptable cultural content to the target groups. Meanwhile, the cultural empowerment of short video is becoming stronger and stronger. Chinese food short video blogger Li Ziqi (YouTube user name: Li Ziqi)[7] and Australian food short video blogger Amy (YouTube user name: Blondie in China)[8] take Chinese food culture as the core of the development of short video through the cultural empowerment method of "Chinese food culture $+"$.

\section{CHINESE RURAL CULTURE IN LI ZIQI'S SHORT VIDEO}

As the creator of Chinese culture short video we media, Li Ziqi has won tens of millions of fans on youtube, and the total amount of video playback has reached more than 2.5 billion, becoming the first Chinese Creator with tens of millions of fans on the platform. In 2020, the Times selected Li Ziqi and 19 other young people from all over the world as "Rising stars: Twenty faces to look out for in 2020"[9]. On February 2, 2021, Guinness World Records announced that $\mathrm{Li}$ Ziqi broke her previous record of "the most subscribed Chinese channel" of 11.4 million on July 16, 2020 with 14.1 million subscriptions, and was listed in Guinness World Records 2021[10].

\subsection{Development Stage of Li Ziqi's Short Food Video}

From March 25, 2016 to May 13, 2017, Li Ziqi's had a difficult time creating short videos. On March 25, 2016, Li Ziqi uploaded her first short video "March 3, peach blossom wine" on the Chinese short video platform Meipai, and created her own video collection "The Seasons Change, Eat as You See Fit". The video is only 2 minutes and 25 seconds, which simply showes the brewing method of peach blossom wine. She then turned to focus more on Chinese food. Each video takes about 2 to 4 minutes and is updated every three to five days. As of May 13, 2017, the period before Li Ziqi's official stopping announcement, videos were 
self-directed and edited by her cell phone, so the picture quality was not clear, and the picture color was not as good as it should be.

The period from May 13, 2017 to May 4, 2019 was a period of rapid development for Li Ziqi's short videos. She officially announced to the public on May 28, 2017 that a team of photographers had been confirmed to help with the filming. On August 22 of the same year, Li Ziqi's team started to enter the world's largest video platform YouTube, releasing the first video on the platform, "What's it like to make a dress for yourself out of grape skins". At this stage, Li Ziqi started to launch five topics, with an average video length of five minutes, and the update frequency dropped from about 15 videos per month to 3-4 videos per month. The video content started to expand from only traditional Chinese food to homemade household items and handicrafts such as Han makeup craft, handmade paper making, green bamboo Luohan bed, solid wood washbasin, movable-type printing, and the Four Treasures of Literature (brush, ink, paper and ink stone), and so on. Following the trend of rapid development of Chinese short videos and platforms, the quality of Li Ziqi's videos made a qualitative leap after she formed a team. Therefore, she won the honor of "Golden Second Awards" of the top ten influential bloggers of microblogging food on August 4, 2017.

May 4, 2019 to present is the mature and stable period of Li Ziqi's short videos. The length of the video at this stage is gradually extended to five to twenty minutes, and the monthly update frequency varies roughly from 1-5 videos. Compared with the previous ones, the content of the video has been innovated, from food production to recording the whole process from planting to making food. The videos at this stage further shape the image of the videos based on the consolidation of the original audience, highlighting the Chinese cultural traits and heritage, and attracting the clicks and attention of new audiences. Li Ziqi has always been committed to showing the rural life that is not known to the city people, and also hopes to tell the most real Chinese story to foreign friends who do not know China through the video. As of May 2, 2021, she has posted 125 videos on YouTube and has 15.2 million subscribers.

\subsection{Li Ziqi's Short Video and Chinese Food Culture}

Li Ziqi was deeply inspired by the culture of Sichuan (a province of China, Li's hometown) cuisine thereby creating the inspiration for making short videos. She once said, "I started doing we-media from a perspective that I am familiar with, and I used to simply want to let my friends in town know where the food they eat came from"[11]. Initially, she simply documented some desserts and drinks that are easy to make, and to show the audiences traditional handmade regional specialties, such as traditional old mooncakes from Chengdu (the capital of Sichuan Province). Very different from the mooncakes in today's bustling city, the handmade mooncakes made by Li Ziqi uphold the local characteristics and style, and hold the taste of her childhood in her memory. The mooncakes are made with melon seeds, peanuts, walnuts, raisins, dipped in sesame seeds on one side and baked to a slight char on the other side, and hand-made into flat circles without the use of molds. Subsequently, Li Ziqi started five topics on YouTube, including "Seasonal diet" and "Sound of blooming flowers", which documented the life of crops from planting to eating and the process of making drinks such as flower tea, respectively. Li has broken the geographical barrier by traveling to Lanzhou, a city in western China, to learn how to make Lanzhou hand-pulled noodles, and also to make her own food creatively using unnamed foods. Her video content is based on a wide range of materials, and the taste is lighter than the traditional spicy Sichuan cuisine. She gradually integrates the characteristics of southeast and Northwest China according to her eating habits, which is considered very traditional and innovative.

Chinese food culture emphasizes the selection of appropriate dishes according to the changes of seasons, and aims to make "complete color, flavor and taste" stand out. In her video, Li Ziqi shows us how to eat light food such as bean sprouts, melons and fruits, cold noodles, jelly and osmanthus cakes to cool down in summer, and cook warm food such as ginger sugar, plum pigeon soup, fish and shrimp, and hot pot in winter, using clear spring water and fruits and vegetables grown in her own yard as ingredients, presenting a self-sufficient, natural and healthy lifestyle.

\subsection{Cultural empowerment of Li Ziqi's short food videos}

\subsubsection{Craftsmanship Spirit}

Li Ziqi started out by making short food videos, and has posted 125 videos on her YouTube channel, 110 of which are directly related to Chinese food practices, and 15 of which show Li Ziqi as a skilled artisan. There are two very unique sections in Li Ziqi's YouTube topic "Oriental intangible cultural heritage" and "Traditional handcraft". The video content under these two topics is novel and extensive, including traditional handcraft techniques such as making Shu embroidery, the Four Treasures of Literature, movable-type printing, papermaking, silk quilts, and so on. Li Ziqi shows us the image of a traditional Chinese woman who is serious and hard-working. She once said in an interview, "When I was a child, my grandfather would weave some bamboo tools to sell for money between farming trips, and I often gave him a hand job"[11]. It is the nurture 
since childhood that has created Li Ziqi's skilled handicraft techniques, and each of her handicraft videos highlights a good quality of Chinese culture - the spirit of craftsmanship. The persistence and refinement of what is carved in the hands and the excellence of what is done is the embodiment of the Chinese craftsmen's pursuit of perfection and excellence. On September 25, 2018, Li Ziqi posted a video on YouTube titled "Bamboo Sofa", which received 58,207,774 views and 1.1 million likes. The video shows Li Ziqi's complete steps from cutting bamboo to making Luohan bed and other traditional Chinese furniture. After watching it, some netizens couldn't help exclaiming: "I struggle to put together IKEA's simplest products and here is she doing everything from scratch", "Her videos make me want to drop everything, move to rural China and make my own everything"[12]. Li Ziqi's video shows a purely handmade concept, reflecting the exquisite skills of traditional Chinese craftsmanship and the meticulous and persistent spiritual quality of artisans, highlighting China's great creativity, vitality and cultural charm.

\subsubsection{Country Life and Seclusion Culture}

Li Ziqi said in an interview, "working in the city is more for survival, while now back in the countryside is more for life". All of Li Ziqi's videos show her audiences a picture of an unrestrained, free and idyllic life. For example, she posted a video titled "The life of purple rice, pumpkins, and ... peanuts" on YouTube on October 11, 2020, which received 30,460,299 views and 580,000 likes. The video is a record of the life of purple rice, pumpkins and peanuts, and as always, it is $\mathrm{Li}$ Ziqi's style. From tilling the soil to selecting and picking peanuts are all done by her alone. In that silent and beautiful yard, Li Ziqi builds a quiet life that everyone in the world dreams of in her own way. One of the comments below the video received 12,000 likes: "They said Liziqi has only Chinese fans. Raise your hands if your an international fans". Below are around 470 responses from fans in different countries. Some netizens said: "What is she cooking-No idea...What is she saying-No idea... What are they eating-No idea...But, hey, I always watch her video. Its gives me peace!!'"[13]. This comment resonated widely. Netizens from different countries left comments expressing their empathy. Although unfamiliar with Chinese culture, the self-sufficiency, love of nature, and peaceful lifestyle conveyed in Li Ziqi's video gave people a sense of satisfaction from the world, making the audiences immerse themselves in it and feel a moment of inner peace outside of urban life.

\subsubsection{The Traditional Chinese Philosophy of "Unity of Man and Nature"}

Li Ziqi's videos are deeply influenced by the Chinese idea of "the unity of man and nature". The various elements of the objects shown in the videos highlight the philosophical idea that man and nature are one and should respect each other. Li Ziqi's "Life" feature videos are about the life of crops. They are born and grow in nature from seeds to flowers and to fruits. Obviously, Li Ziqi is very familiar with the law of development of crops and nature. Not only does she use the power of nature to grow agriculture and become self-sufficient, but also pays attention to protecting the local ecological environment. All the ingredients in her food videos come from natural fruits and vegetables grown in her own small yard. When picking the wild mushrooms growing in the forest, she prefers to select the larger ones, leaving the relatively smaller ones in the mountain forest in order to stagger its growth period. She focuses more on the correct picking techniques, so as to achieve the purpose of maintaining ecological balance and sustainable development. One of Li Ziqi's handicraft video shows that she chooses the right bamboo to take in moderation to make furniture. Her furniture is mostly handmade using nature's products, without chemical products and repeated complicated processing, but in a back-to-basics life where things are used to their fullest, respectful and inclusive.

\subsubsection{Fan Economy}

Fan economy is a business operation mode to obtain economic and social benefits in the form of word-of-mouth marketing by enhancing the stickiness of users. Fans are a huge consumer group and an economic force with potential energy. In the process of fans following Li Ziqi's videos, a series of frenzied consumption behaviors are often generated.

Li Ziqi's videos are unique and almost no one can imitate them. Her videos rely on millennia of traditional Chinese agricultural and handcrafted skills, which are extremely scarce and novel to today's modern society. Based on this, Li Ziqi announced the founding of her own brand Li Ziqi on August 5, 2018, using the network to realize the circulation of goods online and offline under the name of natural handmade and homemade, which has attracted a large number of fans. The brand has only been online for 6 days, and the sales of 5 products have exceeded 10 million. This is not only traffic cashing in, but also an extension of the promoting culture. On the day of "Double Eleven" in 2019, Li Ziqi's Tmall store generated sales of 90 million RMB. On July 4, 2021, Li Ziqi's signing company was invested by ByteDance, holding $1.48 \%$. Meanwhile, the registered capital of the company increased from about 7.04 million RMB to about 7.17 million RMB[14]. As a major giant in e-commerce, the name Li Ziqi not only represents an idyllic lifestyle and cultural attitude, but also the prosperity of the brand's e-commerce marketing. 


\section{CHINESE CULTURE IN THE SHORT VIDEO OF AUSTRALIAN BLOGGER AMY}

\subsection{Development Stage of Amy's Short Food Video}

Compared to Li Ziqi who has a huge fan base and company support, Australian girl Amy seems to be not so outstanding in these aspects. However, as a foreign friend who loves Chinese culture, her short videos are equally unique. In 2014, Amy went to Shanghai to study at Fudan University as an exchange student. This was her first real exposure to authentic Chinese culture. In an interview, Amy said, "China is an ancient civilization with a history of more than 5,000 years, and I was just attracted by the Chinese food and that kind of profound history.[15]" Therefore, she applied to study Chinese at Tsinghua University in 2017 and shared her documented Chinese life on social media platforms. Amy's short videos are mainly about Chinese food, supplemented by traditional Chinese customs, travel and Chinese learning channels. She vlogs about her trip to China, so the production and quality of her short videos tend to be stable. Her short videos are characterized by attractive content, so Amy's food videos on YouTube under the name "Blondie in China" can be roughly divided into the following two stages.

The period from February 25, 2019 to July 28, 2020 is the initial phase of Amy's short food videos posted on the YouTube platform. This period is the initial stage of Amy's tasting Chinese food. During her tour around China, she was curious and new about Chinese food, many of which she tried for the first time with her Chinese friends, which is equivalent to a phase of REACTION videos, while telling the audience about her own taste and feelings. As a native Australian, Amy's narration allows viewers who have never tasted Chinese food to visualize it with their own familiar flavors and whet their appetite. For Chinese viewers, the familiarity of the environment and the food culture further brings Amy closer to them. Meanwhile, in this stage of the video, Amy also tasted some non-Chinese snacks with her friends. Some netizens heartily exclaim: "Her videos will extend the topic. She has her own point of view, which is very deep and she is really understanding a culture before exploring it."

From July 28, 2020 to now, it is the second stage of Amy's short food video development. Amy returned to her motherland Australia due to the pandemic, but she didn't stop exploring Chinese food. In her video "My family tried MALATANG for the first time!" on July 28, 2020, she commented: "I'm gonna continue introducing delicious, authentic Chinese food to my family and friends while I'm here in Sydney. Thank goodness we have such an amazing variety of Chinese restaurants to explore"[16]. During this period, Amy's videos focused on her parents' food tasting at Chinese restaurants in
Australia, and Amy also acted as a Chinese culture expert to explain the historical origins of the food, how to eat it and its taste characteristics. On average, the food videos with parents in them received over 100,000 views and 5,000 to 10,000 likes. Also, at this stage, Amy began to try to make Chinese food by herself. For example, on August 4, 2020, a video with 272,369 views titled "I tried the world's SMELLIEST noodle, Luosifen" recorded Amy's first taste of Chinese river snail rice noodles, which she bought in an instant package to make for her parents[17]. On February 2, 2021, another video titiled "Learn how to make LATIAOZI (hand-stretched noodles) with me!" documented Amy's experience learning to make Xinjiang (a province in China) noodles with a Chinese grandmother and received 57,926 views[18].

\subsection{Cultural Empowerment of Amy's Short Food Videos}

\subsubsection{Chinese Local Characteristics and Folk Culture}

As an Australian who loves Chinese culture, Amy expresses her understanding of Chinese culture through her own actions. on August 25, 2017, Amy debuted her own short video on YouTube, the content of which mainly revolves around the life of travel experiences in various regions of China, with dramatic fluctuations in the number of plays, ranging from as few as 19,000 to as many as 1.62 million. From Gansu (video name: Journey to the West), Shanghai, Beijing to Xi'an, Hangzhou (a tea paradise), Shenzhen (China's Silicon Valley), the number of cities she has visited and her understanding of the history and culture of each city even surpass some Chinese. Some Chinese netizens commented: "Somehow, I feel these videos are so educated, even me as a Chinese find it interesting". Amy has been immersive in experiencing the real Chinese cultural life in the form of vlog, and has carried out large-scale explanation and popular science at length. Walking and talking leads to slightly shaky images, neat city streets and noisy crowds are all part of the real China that Amy brings to the audience through her videos. Her knowledge of Chinese history and geography, as well as her curiosity and exploration of local customs and lifestyles, can be seen in the videos she makes with care.

On January 21, 2020, Amy's video "What's a Chinese wedding like?" hit a short-term peak in terms of video views and likes. Obviously, many people are interested in traditional Chinese folk culture, so Amy documented her first Chinese wedding in Fuding, Fujian Province, by comparing a game of guessing at the wine table to extremely complecated version of scissors paper rock through her western eyes. Although Amy is puzzled by customs such as barricading doors and 
hiding the bride's shoes, she says: "I don't know if all Chinese weddings are this way, but so far I'm getting the vibe that Chinese weddings are very light-hearted and fun"[19]. Netizens from various countries also shared their Chinese weddings in the comment area. It can be seen that Amy helps herself better understand a new culture by comparing what she already knows, and it is refreshing and enjoyable for her to explore the customs of a new culture in a new perspective.

\subsubsection{Intercultural Exchange between China and Australia}

Among Chinese short food video bloggers, Amy is also a fan of LIZIQI. On February 18, 2021, she uploaded a REACTION video - "My parents watch LIZIQI for the first time", which received 286,981 views and 10,000 likes, a short-term peak in views and likes[20]. The video Amy and her parents watched is titled “Chinese New Year's decorations, goods and snacks" uploaded by Li ZiQi on February 10, 2021. This REACTION video is a good reflection of Amy's knowledge of Li ZiQi and Chinese culture, as she talks to her parents about Chinese culture while also discussing with them what she is unsure about. Amy would mention Li ZiQi's excellent craftsmanship to promote her father's own craft studio in passing, would be inspired by the way Li ZiQi makes shrimp, would be amazed by her skill at making Chinese candy canes, and would educate her parents about the importance of seeds for Chinese New Year. Amy mentioned that she had dreamed about making a Li ZiQi-style video, for which she personally purchased and planted flowers to create a small flower bed of her own, and the radishes she harvested three months later filled her with satisfaction.

In the process of cultural exchange between China and Australia, Amy has served as a medium to connect the two sides well. In the face of new things, she bravely tried and spreaded it to her parents. In a video titled "Why I love China" on July 9, 2018, Amy tells a heartwarming story about her travels in China and heartily exclaims: "These moments of pure human experience is what the world needs more of. We just need to open ourselves up to these experiences and it can quite literally change our life or our perspective on it'[21].

\section{ANALYSIS OF THE CULTURAL COMMUNICATION EFFECT OF CHINESE SHORT FOOD VIDEOS}

Communication effect refers to the effective results produced by the act of communication. This result is reflected in the cognitive, the thinking and emotional level, and the volitional level of both the transmitter and the receiver, including the increase or decrease of knowledge level, the change of value system, and the change of adherence to and support of something. The effect of short video communication mainly depends on the communicator, the content, the communication environment and the communication method. In the pan-entertainment new media environment, short video development is in the dividend period, but there is an urgent need for quality content to flow to the market. Chinese short food videos take Chinese food culture as the core, while deriving cultural symbols and products with cultural empowerment. The video has formed its own advantages and characteristics in both content and form, and can be said to have broken out into a world of its own.

\subsection{Features of Short Videos New Media in Spreading Food Culture}

\subsubsection{Immersive Experience and Interactivity}

Compared with other types of videos, short food videos pay more attention to the audiences' experience and adhesion in the process of communication, and have a sense of traceability and teaching. By filming the preparation of food, the production process and the final dishing up with certain techniques and camera angles, it can greatly stimulate the audience's sense of participation, empathy and enhance interactivity and closeness in the process of communication. Short food videos have the advantage of producing series of episodes, leading audiences into the world of food again and again through the ultimate sense of images. The strong output of content and the matching of sound and music can indirectly stimulate the sense of smell and taste that cannot be felt by the audiences in visual, auditory and perceptual aspects, thus keeping the content attractive and fresh to a certain extent, and also enhancing the audiences' sense of immersion experience.

\subsubsection{Wide Spread and Deep Layers}

In the new media context, short videos have a different audience group, which is more diverse, from traditional video forms. Differences such as race, education, religion, income, gender exist among individual audiences, who select and decode media content based on their own needs, attitudes and values. However, food is something that all human beings can sense and are willing to accept. The wider selective exposure of audiences to such content has contributed to the expansion of the scope of communication, while reflecting the deepening of the communication layer.

Changes in the shallow cognitive level are reflected in data such as the number of plays and likes, which indicate changes in the audiences' knowledge of the video content, and also show the audiences' willingness to accept such content from the side. The middle level 
of thinking and emotion reflects the understanding and appreciation of the video content by the audience, which means leaving a comment in the comment section expressing agreement with a point of view. Eventually to a deep level of will and personality. This level requires even more support and loyalty from the audience of the video content, as shown by the consolidation of the number of followers of the communicator, the positive comments in the comment area, and even the presence of netizens who show the food they have been inspired to make and taste.

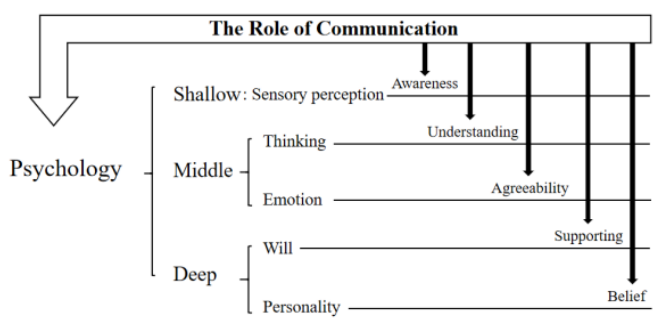

Figure 1 The role of communication in the psychological system at the deep and shallow levels and its measurement[22]

\subsubsection{Much Empowerment and High Acceptance}

In the new media era of fragmentation and pan-entertainment, it is extremely important for short videos to ensure the quality of the communication content in order to attract a strong sense of recognition from the target audience. The short food video has gained a place in the competition of short video content with its diversified and stylized production form and aesthetic taste. The high added value brought by quality content due to its high acceptance proves its empowering multi-disciplinary character, a characteristic reflected in many aspects such as economy, culture and language. Chinese short food videos are gradually building up a unique cultural symbol through the production and promotion of Chinese and foreign creators, taking Chinese food as the core of development and giving it other development paths in multiple fields. In the independent development of each empowered individual, but also in the whole system can form a holistic collaboration, the comprehensive formation of China's food short videos own unique advantages, to further strengthen the power of communication, deepen the communication effect.

\subsection{Commonalities and Characteristics of Chinese and Foreign Communicators in Short Food Video Communication}

As the saying goes, "A culture that is national is also international", the tangible carrier transcends national boundaries, and the characteristics and heritage of different nationalities create the plurality and richness of the world's cultures. Carl Hovland, a famous American communication scholar, pointed out in Communication and Persuasion that the final effect of communication is not determined by the subjective will of the communicator, but is influenced by various factors such as the characteristics of the communicator, the arrangement of the message content, the way the message is presented, and the communication medium[23]. As a result, Chinese food culture is also subject to similarities and differences in cross-cultural communication.

\subsubsection{Similarities}

The appeal beyond cognitive boundaries and the promotion of cultural exchange are commonalities in the cross-cultural communication of Chinese cuisine. Under the phenomenon of pan-entertainment, both Li Ziqi and Amy realize that what is outside the audiences' congnition is what is most attractive to them. The attraction of culture is always greater than the attraction of material things. Li Ziqi's video contains the accumulation of 5,000 years of traditional Chinese culture. In the process of cross-cultural communication, Li Ziqi presents Chinese cuisine in the simple lifestyle of the idyllic countryside. In telling the story of a completely different lifestyle from the city, she is under the context of agricultural culture, which is different from industrial culture, to show China and the world a way of life that is inaccessible to them but universally desired and accepted. The same sense of novelty that attracted Amy from Australia to learn about Chinese culture is the "I've never experienced it in Australia". Amy shows the different food cultures in different regions through her travels and life experiences in China. Her personal experience not only gives Chinese netizens a new sense of foreign perspective, but also gives people from all over the world a better understanding of real Chinese life. Both Li Ziqi and Amy break the audiences' expectation of traditional short food videos through exotic cultures, and help them escape from their anxious, fast-paced lives through the combination of tradition and modernity, so they are easy to empathize with, thus enhancing audience bonding.

The benefits of Li Ziqi and Amy's short food videos in promoting cultural exchange cannot be overstated. As Li Ziqi's videos have become more and more professionally produced and the chosen topics more and more interesting, her videos have attracted and influenced some people from different countries to a certain extent. Amy is one of them. Her early videos show her tasting delicious food, experiencing traditional Chinese culture such as Chinese Kung Fu, calligraphy and tea ceremony during her trip. If Li Ziqi is showing traditional, agricultural part of China to the world through the rapid development of industrialization, which to some extent creates a lot of one-way communication, then Amy is spreading two-way 
communication by experiencing Chinese culture and talking about Australian customs. As Amy said, "I want to be the China girl. I want to be the Australian ambassador for China and the Chinese ambassador for Australia"[24]. Either form shows friendliness and authenticity, and has greatly contributed to the folk cultural exchange.

\subsubsection{Differences}

The difference in narrative style and subjective perspective is an obvious difference in communication between Chinese and foreign communicators. In the process of cross-cultural communication, language is an important tool to complete the encoding and decoding of information. Amy mostly speaks English, an internationally accepted language, to express herself in her videos, with bilingual subtitles. Each of her videos presents a hilarious atmosphere under the output of fast speech speed. With the development of mobile social networks, audiences from different countries, nationalities and cultural backgrounds can communicate and exchange cultures with the help of short videos, in which the main role is played by non-verbal symbols. Compared to Amy's video style, Li Ziqi mainly shows the aesthetics of life through the lens language of clothing, plants, natural scenery, architecture, artifacts and background music, presenting a documentary-style slow-paced lifestyle. It actually brings a strong viewing experience to Chinese and foreign audiences from the visual and auditory levels. It can be said that the biggest difference between Amy and Li Ziqi's video is that Amy is telling the story with language, while Li Ziqi is telling the story with images.

As a native of Sichuan, China, Li Ziqi's videos are based on her hometown. The scenes and props used in her videos are a reflection of Li Ziqi's real life in the countryside. She expresses the Chinese cultural and her feelings about this unique way of life through the camera images, background music and other symbols. As she said herself, "I am just sharing my life". As an "foreigner" to Chinese culture, Amy makes videos with the mindset of trying and experiencing a new culture. She once said, "Maybe the representation that you see of China and Chinese people on the media is just not true. And a lot of why I started this YouTube channel is to try to change that perception"'[25]. Amy shows the true perception of the people through her own perception of Chinese culture from a foreigner's perspective. Her videos are mostly about "first time" and "novelty", reflecting the friendship and harmony of folk communication.

\section{CONCLUSION}

Media culture is prevalent in the Internet era. The Impact of Social Media on National Cultural Security in the Context of Globalization mentions that "Visual concept, sound and images, especially the latter, dominate in contemporary culture"[26]. It is evident that visual image symbols bring more intense sensory sensations to the audience. Niklas Luhmann explores the significance of media technology for the existence of culture and whether the place and change of culture in the media environment and history means the death of culture. Facing the situation of short video pan-entertainment, Chinese cultural short video bloggers such as Li Ziqi and Amy have become unique cultural symbols. Through their personalized self-development mode, they are committed to building a good Chinese short video media ecology with a variety of empowerment based on Chinese food culture.

Throughout its long history, China has been perceived by Western society in a variety of ways[27]. Li Ziqi and Amy's short video not only enhances Chinese people's cultural identity in cross-cultural communication with both Chinese and foreign perspectives, but also gives the world a further real understanding of Chinese culture. The era of big data has led to the rapid development of the short video industry. Traditional Chinese culture intermingles with the modern short video industry to empower short videos and promote modern media culture to be more adaptable to social development, as a way of paving the way for the exchange between Chinese culture and the world.

\section{REFERENCES}

[1] China Internet Network Information Center. (2021) The 47th China Statistical Report on Internet Development.

DOI: http://www.gov.cn/xinwen/2021-02/03/5584518/fil es/bd16adb558714132a829f43915bc1c9e.pdf.

[2] iResearch Consulting Group. (2018) 2018 China's Short Video Marketing Report. DOI: http://www.iresearchchina.com/Upload/201812/20 181211020207_1888.pdf.

[3] Cunningham, S., Craig, D. Online Entertainment: A New Wave of Media Globalization?. International Journal of Communication, 10(2016), 5409-5425.

[4] Postman N. (2006) The Huxleyan Warning. In: Andrew P. (Eds.), Amusing Ourselves to Death. PENGUIN BOOKS, New York.

[5] McChrystal S. (2015) Team of Teams: New Rules of Engagement for a Complex World. Portfolio Penguin LTD, New York.

[6] McLuhan M. (2001) Understanding Media. Routledge, London.

[7] Li Ziqi (YouTube), 2017. Li Ziqi. DOI: https://www.youtube.com/c/cnliziqi/videos. 
[8] Amy (YouTube), 2017. Blondie in China. DOI: https://www.youtube.com/c/BlondieinChina/playlis ts.

[9] The Sunday Times, (2020) Rising stars: Twenty faces to look out for in 2020. DOI: https://www.thetimes.co.uk/article/rising-stars-twe ntyfaces-to-look-out-for-in-2020-kwcmc8mzf.

[10] Guinness World Records, (2021) Most subscribers for a Chinese language channel on YouTube. DOI: https://www.guinnessworldrecords.com/world-reco rds/622868-most-subscribers-for-a-chinese-languag e-channel-on-youtube.

[11] YouTube user zuo Quan, (2019) Liziqi’s interview (English subtitle). DOI: https://www.youtube.com/watch?v=qrEzVL7h40g.

[12] Li Ziqi (YouTube), 2018. Bamboo Sofa|Liziqi channel.

DOI: https://www.youtube.com/watch?v=LTejJnrzGPM.

[13] Li Ziqi (YouTube), 2020. The life of purple rice, pumpkins, and ... peanuts. DOI: https://www.youtube.com/watch?v=rJSZfrJFluw.

[14] Dao News. (2021) ByteDance invests in rural Chinese influencer Li Ziqi. DOI: https://daoinsights.com/news/bytedance-invests-inrural-chinese-influencer-li-ziqi/.

[15] Youth Consumption (qnw.cc), 2021. This Australian lady loves Chinese food. DOI: http://www.qnw.cc/cunguan/stgw/16786.html.

[16] Blondie in China (YouTube), 2020. My family tried MALATANG for the first time. DOI: https://www.youtube.com/watch?v=a4jxyKjbN3A.

[17] Blondie in China (YouTube), 2020. I tried the world's SMELLIEST noodle, Luosifen. It's made from snails... DOI: https://www.youtube.com/watch?v=z28nXtGutII.

[18] Blondie in China (YouTube), 2021. Learn how to make LATIAOZI (hand-stretched noodles) with me! DOI: https://www.youtube.com/watch?v=eJsh9-Zgzxw.

[19] Blondie in China (YouTube), 2020. What's a Chinese wedding like? DOI: https://www.youtube.com/watch?v=NyR3s5AUVA E.

[20] Blondie in China (YouTube), 2021. My parents watch LIZIQI for the first time. DOI: https://www.youtube.com/watch?v=UT3whFVWq _o.

[21] Blondie in China (YouTube), 2018. Why I love China. DOI: https://www.youtube.com/watch?v=heEvqPAUf4.
[22] Lin Zhida, Guo Qing (docin.com), 2006. The Hierarchy of Communication Effects. DOI: https://www.docin.com/p-1998355405.html.

[23] Hovland C. (2015) Communication and Persuasion. Communication University of China press, Beijing.

[24] UNILINK (Sohu.com), 2019. The Australian lady aspires to be a Chinese Internet celebrity. DOI: https://www.sohu.com/a/359264508_100270508.

[25] Blondie in China (YouTube), 2019. Why I love visiting remote Chinese cities. DOI: https://www.youtube.com/watch? $\mathrm{v}=\mathrm{pFEzXZdrgP8}$.

[26] Xin L. (2018) The Impact of Social Media on National Cultural Security in the Context of Globalization. Shandong people's publishing house, Shandong.

[27] Jones, D. M. (2001) The Image of China in Western Social and Political Thought. Palgrave Macmillan, London. 